\title{
Persistent vaginal bleeding in a patient with a broken Implanon ${ }^{\circledR}$
}

\author{
Sally Pickard, MBBS, DRCOG, Staff Grade; Lesley Bacon, MB BChir, MFFP, Consultant, Department of Reproductive Health, \\ Lewisham Primary Care Trust, London, UK
}

Correspondence: Sally Pickard, Department of Reproductive Health, Lewisham Primary Care Trust, St Giles Road, London SE5 7RN, UK. Tel: +44 (0) 207771 3330. Fax: +44 (0) 207771 3338. E-mail: s.pickard@macunlimited.net

(Accepted $16^{\text {th }}$ July 2002)

The Journal of Family Planning and Reproductive Health Care 2002: 28(4): 207-208

\begin{abstract}
A 29-year-old woman with an Implanon $^{\circledR}$ contraceptive device in situ presented with persistent and prolonged vaginal bleeding. The implant had been inserted 2 years previously; the patient had been happy with it and had been mainly amenorrhoeic with the occasional light period. She was concerned that the implant had broken during a game of 'rough and tumble' with her son in August 2000. Since the trauma to her arm her bleeding pattern had changed, and she began bleeding heavily for 3 weeks every month. The rod was removed and found to be fractured halfway across its width. A new Implanon ${ }^{\circledR}$ device was inserted and the bleeding settled.
\end{abstract}

\section{Case report}

This patient was fitted with an Implanon ${ }^{\circledR}$ contraceptive device in December 1999, in her right (non-dominant) arm, using the standard technique and without complications. When she was reviewed 5 weeks later she reported no problems, although she felt that the implant had moved. She had had no bleeding per vagina since insertion of the device. Upon review 6 months later she mentioned that she had had an infection around the Implanon ${ }^{\circledR}$ site, which had settled. On inspection the site was healthy, the rod was straight and easily palpable subdermally. She occasionally had light periods but was otherwise amenorrhoeic.

She was seen again in January 2001, 6 months after her previous check-up. She had bled heavily for 4 weeks in October 2000, and reported that she thought the Implanon ${ }^{\circledR}$ rod had snapped during a game of 'rough and tumble' with her 7-year-old son. She had seen her general practitioner (GP) who agreed with her. The patient and the family planning consultant, from whom the GP had sought advice (LB), contacted the manufacturer's helpline and were given the same information. They were advised that it was very unlikely that the device had snapped and that contraceptive cover would not be lost in this situation. The patient was reassured.

The patient attended again for a check-up a year later in January 2002. She complained of prolonged heavy bleeding lasting 3 weeks every month for the previous 5 months which she found unacceptable She was otherwise asymptomatic. She had had a stressful year and had been diagnosed as having an eating disorder (her weight had dropped from 64 to $51 \mathrm{~kg}$ ), for which she was receiving outpatient treatment. She requested that the Implanon ${ }^{\circledR}$ rod be changed as she was sure it had snapped, was not working, and was the cause of prolonged heavy bleeding. This was discussed in the clinic and other causes for the bleeding explored. The patient was up-to-date with her smears and was in a stable, mutually monogamous relationship for many years. She was still bleeding at this point and declined examination.

Arrangements were made to remove the device and insert a new one. It was easily palpable subdermally and was felt to be in a C-shape. It was removed using the manufacturer's recommended technique, without complications. On removal it was examined and it was noted that the device was bent and also fractured across half its width, halfway along its length (Figure 1). A new implant was inserted according to the manufacturer's instructions. The patient was reviewed 2 weeks later, the heavy bleeding had settled, the Implanon ${ }^{\circledR}$ rod was palpable and straight, and the insertion site looked healthy.

Figure 1 The broken Implanon ${ }^{\circledR}$ device following its removal from the patient

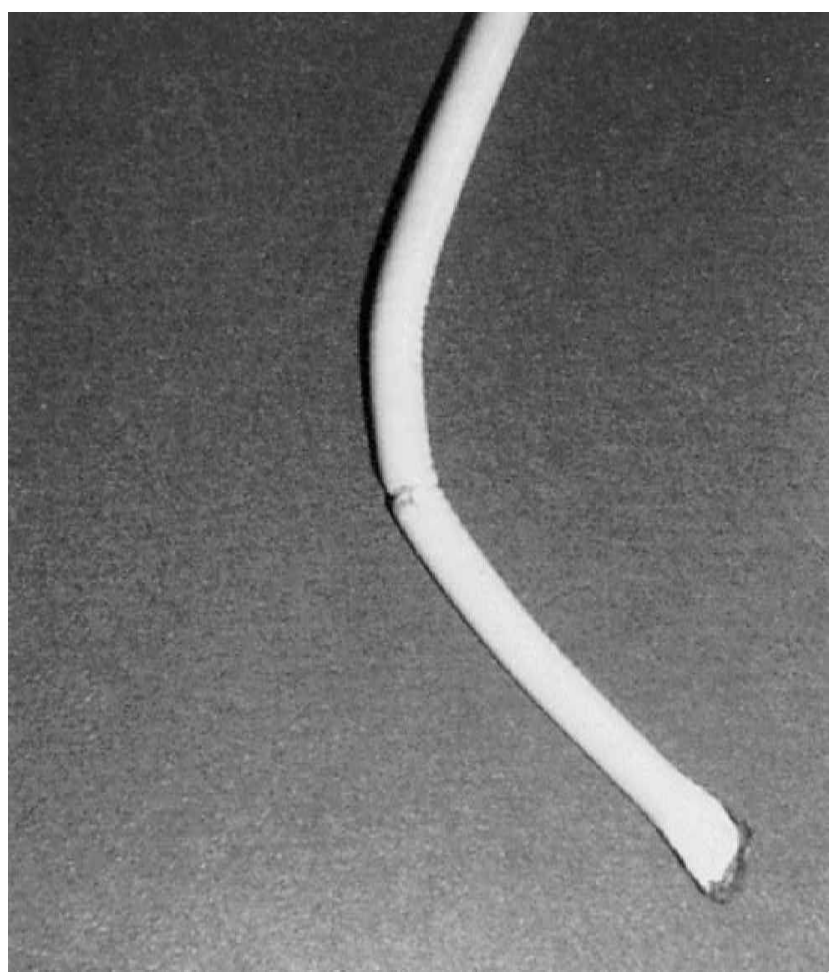

\section{Discussion}

This is the first case, of which the authors are aware, of an implant becoming fractured. In a review of clinical studies of Implanon ${ }^{\circledR}$ in 1999 , three broken implants were mentioned as a cause of complicated removal procedure. Whether the implant was fractured prior to commencement of the procedure or during the procedure is not made clear. ${ }^{1}$ 
Implanon ${ }^{\circledR}$ consists of a core and a membrane. The core contains $68 \mathrm{mg}$ etonogestrel dispersed in a matrix of ethylenevinylacetate (EVA) co-polymer and the external membrane is made of EVA co-polymer $(0.06 \mathrm{~mm}){ }^{2}$ This differs from the Norplant subdermal contraceptive device in which the levonorgestrel powder is free within the silastic cavity, and if this cavity is broken the powder will be dispersed. The specific design of Implanon $^{\circledR}$ ensures a controlled release of etonogestrel over 3 years.

It is not possible to say that the prolonged heavy bleeding experienced by the patient described in this case report was due to the broken implant. In fact, 10-20\% of women using Implanon ${ }^{\circledR}$ will have prolonged bleeding at some point. ${ }^{1}$ In addition, there were other possible causes, including the fact that the patient had lost a lot of weight and suffered severe stress during this time. However, it remains a possibility that because of the disruption of the specially designed, controlled release mechanism, varying amounts of etonogestrel were being released which may have been responsible for the prolonged bleeding in this patient. When the implant was replaced with a new device the bleeding settled. Another concern would be that the effectiveness of Implanon ${ }^{\circledR}$ as a contraceptive could be diminished if the rate-releasing mechanism is disrupted, although there is no evidence for this.

This case report is important in that it is the first to demonstrate that an Implanon ${ }^{\circledR}$ device can be fractured in situ. The clinical significance of this is unknown, but it if a fractured device is suspected then we would recommend that it be replaced.

\section{Acknowledgement}

This case report is printed with the kind permission of the patient concerned.

Statements on funding and competing interests

Funding. None identified.

Competing interests. None identified.

References

1 Edwards JE, Moore A. Implanon. A review of clinical studies. $\mathrm{Br} J$ Fam Plann 1996 24(4)(Suppl.): 3-16.

2 Guillebaud J. Contraception: your questions answered (3rd edn). London: Churchill Livingstone, 1999.

\title{
Intra-vas deferens injection of styrene maleic anhydride gel for male contraception: Is it safe?
}

\author{
A K Singh, MPhil, PhD, Consultant, School of Environmental Sciences, Jawaharlal Nehru University, New Delhi, India
}

Correspondence: A K Singh, School of Environmental Sciences, Jawaharlal Nehru University, PO Box 10501, Olof Palme Marg, New Delhi 110067, India.Tel: +91 11 6167439/6168259.Fax: +91 11 6169962.E-mail: dranilksingh@indiatimes.com

(Accepted $16^{\text {th }}$ August 2002)

The Journal of Family Planning and Reproductive Health Care 2002: 28(4): 208-209

\section{Introduction}

In developing male contraceptives, scientists have mainly focused on inhibition of spermatogenesis by hormones or the obstruction of sperm transport by an occlusive process. Ongoing male contraceptive research in India is looking at injecting the co-polymer, styrene maleic anhydride (SMA), dissolved in dimethyl sulphoxide (DMSO), into the lumen of the vas deferens. ${ }^{1-6}$ The polymer obstructs or partially obstructs the transport of sperm and exhibits a spermicidal action.

Can a safe male contraceptive be developed out of the three constituent chemicals, styrene, maleic anhydride and DMSO? Styrene or styrene oxide is mutagenic, clastogenic and possibly carcinogenic. ${ }^{7-11}$ In 1994 the International Agency for Research on Cancer (IARC) classified styrene oxide as probably carcinogenic to humans (Group 2A) and carcinogenic to animals. ${ }^{11}$ Similarly, maleic anhydride has been reported to induce malignant tumours in rats ${ }^{12}$ and is mutagenic to hamster lung cell. ${ }^{13}$ The teratogenic nature of DMSO has been known to the scientific world for the last $30-40$ years. ${ }^{14}$ All the constituents of this male contraceptive agent are, therefore, actually or potentially injurious to humans.

Research on adult monkeys has shown that $400 \mathrm{mg}$ of SMA gel is required to fully occlude the vas of male monkeys. ${ }^{3}$ Lower doses of 200, 33.3 and $16.65 \mathrm{mg}$ did not occlude the vas but led to dead or abnormal sperms appearing in the ejaculate. ${ }^{3}$ Abnormal sperms have also been detected in human ejaculate after the use of SMA gel to occlude the vas. ${ }^{1,5}$ In the case of human subjects, a single dose of SMA co-polymer (40, 80 or $140 \mathrm{mg}$ individually) can cause infertility on account of azoospermia and teratospermia. ${ }^{1}$ After injection there was massive reduction of sperm counts, the sperms voided being of poor quality with low motility and viability, in addition to the sperms being abnormal. ${ }^{1}$ Some parameters of sperm quality show signs of reversibility. ${ }^{1}$ But contraception is still maintained for up to 10 years at least. ${ }^{6}$ However, long-term infertility because of azoospermia or teratospermia might indicate the potential for future serious pathologic conditions, most notably testicular tumour or endocrine disruption, that could impair spermatogenesis and fertility if reversal is required.

\footnotetext{
Discussion

Sperm death

There are two proposed mechanisms for sperm death. The first is that sperms are killed by a $\mathrm{pH}$-lowering effect. ${ }^{1-3}$ According to this mechanism, the co-polymer of SMA dissolved in DMSO is injected into the vas lumen and reacts with the cellular secretion, forming a stable precipitate within the lumen and making the environment inhospitable so that sperms passing through it are killed by the lowered $\mathrm{pH}$. The average normal value of $\mathrm{pH}$ of the vas lumen in the absence of any foreign agent turns out to be 7.2. ${ }^{3}$ However, after injection of SMA co-polymer the $\mathrm{pH}$ level reduces to 5.6. ${ }^{3}$ Is sperm death actually due to the lowered $\mathrm{pH}$ ? An
} 